\title{
Research on Urban Brand Image Design Integrating Regional Culture
}

\author{
Jia You \\ School of Fine Arts and Design, Yancheng Normal University, Yancheng, Jiangsu224000, China
}

\begin{abstract}
Urban brand image essentially reflects the regional culture, revealing the core spirit and culture of the city, and embodies value pursuit and development concept, which shows spiritual symbol of unique distinctive and specific temperament. To enhance the internal cohesion and arouse the cognition of city brand, it is vital to make the city brand known worldwide. We should deeply tap the profound connotation of regional culture, extract elements, strive to create a more attractive city image, and create unique regional culture of an internationally influential brand.
\end{abstract}

Keywords: Regional culture, City brand, The image of city, Design.

Regional culture is the cultural characteristics and historical accumulation of the city, city brand image is a distinct mental bond between city and world. Regional culture and urban brand image have huge intangible value, bearing the weight of historical memory and human struggle. A good brand image can not only improve the cohesion of the city, promoting the construction of spiritual civilization and material civilization, but also can show the world natural, social and humanistic beauty of the city. City is the most important form in the development of human civilization. China has thousands of years of urban construction history, and the regional culture is long and brilliant. When entered the industrial age, urban brand image has weakened. Many brands are not integrated into the regional culture, and excellent traditional culture has not been developed. Many city brands neither can represent the city, nor are recognized by the mass.

\section{The Relationship of Regional Culture and Urban Brand Image}

\subsection{The Characteristics of Regional Culture}

Regional culture refers to the special identification elements, the sum of material culture and spiritual culture in a specific region. Material culture includes geographical climate, mountain and river shape, architectural feature. Spiritual culture contains folk customs, value opinions, cultural traditions. Regional culture has the following characteristics: regional. Ten miles of different sounds, a hundred miles of different customs. Different regional cultures have its own obvious characteristics in geography, life, language, custom, diet, architecture style. For example, the city brand of Kunming is positioned as spring city. Nationality, different national cultures and forms have colorful lifestyle, and are in the mutual infiltration, reflecting inclusiveness of the Chinese national culture. Historic, the city itself is a history. Each city has its own unique history and story. Historical culture inherits in the changes of cities.

\subsection{Summary of Urban Brand Image}

Brand is the core competitiveness of products, adhering to product technology, design, function, and other properties. People buy any kind of products based on brand loyalty. City brand is virtually the essence of city, namely branding the city image, which carries the function, emotion and label, and reflects the appearance and spirit of the city. City brand is equal to a business card, shaping the city's first impression, such as fog capital London, motor city Detroit, water city Venice. Since ancient times, China's Heaven-Suzhou and Hangzhou have attracted countless people. "March is a good time to watch fireworks in Yangzhou" is to mention geographical climate characteristics of refining city. In essence, brand marketing is to its intuitive reflect and overall evaluation, extracting the characteristics and style of the city. The brand image design should follow the unique logo of the city, witnessing history, engraving memory and inheriting context, which is a special branch in the region.

\subsection{The Function of Regional Culture in the City Brand Image Design}

Firstly, the regional culture is the basic power to create city brand image, and is also the source of urban brand image design. Making the locals establish the sense of belonging and identity is that forms brand identity to outsiders. Regional culture makes city show a unique charm and style, relying on the local culture to promote the development of the city better. Secondly, the regional culture determines the urban brand design, whose material is regional culture. Regional cultural differences will affect brand design, forming its stability and unity. For example, brand image of Suzhou garden water town, Shanghai's fashion city, Shenzhen entrepreneurship city. Thirdly, in the city brand design, the regional culture reflects the heavy historical and cultural value, unique arts and humanities value, good social and economic value. Such as creating cultural and tourism brand relying on the regional culture, inheriting the historical culture, developing the spirit of humanism, descending traditional art, improving regional economy, constructing beautiful city.

\section{The Current Problems of City Brand Image Design}

\subsection{Cities Lack of Regional Culture Characteristics}

Taste, fashion and consumption in the industrial age are impacting regional culture. More than 30 countries have an 
urbanization rate of exceeding $80 \%$ in the world. Urbanization means high-rise buildings, which leads to regional culture characteristics gradually disappear. China's urban construction has the phenomenon of that thousands of cities have one side, and urban architecture lacks regional characteristics, a prosperous scene of industrial civilization, but it lacks historical precipitation. There is neither internal identity nor external identification in regional culture. According to Ganging daily, large-scale demolition and construction are common in major cities. The annual demolition of old buildings in China has reached $40 \%$ of additional construction. There are large squares demolished in 4 years and Olympic stadium constructed less than 20 years, which are far from the designed life and waste is very serious. The rapid development of real estate has created a large area of reinforced concrete forest, which leads to the lack of personality of the city image.

\subsection{Confusion of Brand Image and Regional Culture}

On the one hand, the brand image is not deeply integrated with the urban regional culture, and cannot show the regional characteristics. For example, many urban landmarks are incompatible with regional culture, even garden city Suzhou, which has also been criticized for introducing landmark buildings in the style of London Bridge. Such phenomena are also common in other cities, such as Lhasa square invested by 24 billion yuan in Chongqing, glass pyramid in Shaoxing. On the other hand, ancient style is popular for tourism, and development is relatively serious. Divorced from the cultural characteristics, geographical climate, and local customs, deliberate innovation has resulted in extravagance and waste, reflecting the idea of shortsightedness. In the urban brand image design, one-sided pursuit of high, large, ancient, foreign, strange and luxury, only exists traditional and innovative coat, but lacks of the essence of regional culture.

\subsection{The Absence of Brand Image Design Innovation}

The visual identification system remains to be improved, the single pursuit of logo construction in the development of urban brand image, emphasizing the hardware construction area, road, boundary, node, markers and other elements, paying attention to the planning of urban landscape but neglecting the cultivation of humanistic spirit. The concept of brand image has not formed, causing the lack of its connotation, due to the complexity of city brand image content, in whose process, many cities have not made people establish first impression, nor do they display the essence of the image in front of everyone. At present, designers generally fail to distinguish the two cities with marked characteristics, lack of innovative representations, especially insufficient in inductive extraction, color fusion, graphics expression.

\section{Design Strategy of City Brand of Integrating Regional Culture}

\subsection{The Positioning of City Brand Image Design}

The design should adjust measures to local conditions, fully consider the local resources and environment, and understand comparative advantage of the city. On this basis, the functional types of cities are positioned, such as economic, technological, historical, and cultural. According to the history of the city, orientating spirit and culture can reveal personality of the city. In the design orientation, we should fully understand the needs of people and their understanding of urban culture, and integrate folk customs into the urban brand image. In brand positioning, we should directly express the characteristics of the city through naming, such as mountain city Chongqing, hero city Nanchang, Sun City Lhasa, ice city Harbin, coal capital Fushun. Taking Harbin as an example, it is not because the weather is cold that it can be called an ice city, but because Harbin has the largest ice and snow event in China, the snow culture is well-known all over the world and has a strong brand influence. In the positioning of brand image, we should base on regional characteristics and tap the core value of urban brand. For example, the landmark building of the Oriental Pearl Tower in Shanghai shows Shanghai's ambition to become an Asian financial center and an international metropolis. The Oriental Pearl Tower is designed with lighting system and touch the sky capsule, combing culture, entertainment and science fiction. It has refined the regional cultural characteristics of Shanghai., reminding people of the Oriental Pearl of Shanghai.

\subsection{The Application of Regional Culture Element}

To refine regional cultural elements, we should enhance cultural self-confidence and internal identity, and make urban brands known to the world. In the historical and cultural ancient city, the material cultural heritage can be used, such as the Forbidden City, the Great Wall and the Terracotta Warriors, to highlight the urban characteristic landscape and inherit historical and cultural heritage. The brand is the fusion of the logo, name and symbol, regional culture can be highlighted by way of places of historic interest, and the inheritance of historical context can be realized. For similar experience, reference can be made to Cambodia's series of signs based on the silhouette of Angkor Wat abroad, and to the design experience of Beijing Forbidden City, Xi'an wild goose pagoda and Hangzhou West Lake at home. Intangible cultural heritage includes various folk customs, skills and cuisines. For example, Inner Mongolia can show the ruggedness and hospitality of the Mongolian people. In the northeast and other old industrial base cities, the application of industrial cultural elements is emphasized, extracting industrial cultural landscape and constructing industrial civilization landmark. Such as outstanding technology, which is supreme pragmatic thinking in the design, and the construction of industrial buildings. In the development of the ancient city, Northern Shaanxi caves and other buildings can be displayed to the world as urban brands, and integrate green development and ecological architecture to improve brand influence. In coastal cities, economic development can be combined with urban brand design to enhance the appeal of regional culture.

\subsection{The Improvement of the Brand Design and Promotion System}

Urban brand image design cannot simply rely on one logo, several signs or historical sites. Instead, we should select the 
characteristic elements that can best represent the city for refining, expressing them in various ways such as sports language, text, vision and other ways. The way of great impact can be adopted, visual image (VI), behavioral image (BI) and conceptual image (MI) are applied to the design of urban brand to give people the impression of the whole city and interpret it in visual language. For example, the city logo of Qinhuangdao is chosen as the emperor of Qin, which shows the profound heritage of Chinese culture, coupled with projects such as the Great Wall tour and several theme image slogans, it accurately positioned the city image. One of the typical slogans is "Suzhou and Hangzhou in the South and the emperor of Qin in the north", which improved the influence of the city. Brand design should also reflect the designers' professional ethics and value judgment, highlighting originality, artistry and professionalism, using the unique spirit of brand design to express the spirit of place and individual, which fully reflects the public's aesthetics. In order to enhance brand influence, in the information age, we should pay more attention to make more use of information technology and mobile Internet to spread regional culture, and be good at making use of major activities such as the Olympic Games, Winter Olympics and World Expo to enhance the influence of the city. In the design, we should pay attention to that the development of the city is people-centered, and the formation of the brand needs the recognition of the outside. In a long-term accumulation process, we must adhere to the people-oriented principle, and must not be eager for quick success and instant benefit, not engage in formalism and false propaganda.

\section{Conclusion}

City is the carrier of material and spiritual culture, and regional culture is the core value of city brand. In the design of urban brand image, we should base on regional culture, develop core values, better inherit historic culture, show urban style, and build an urban brand image system, to realize the expression of urban core characteristics.

\section{References}

[1] Zhao Xiaofang. Design expression of regional culture in urban brand image $[\mathrm{J}]$. Popular Literature and Art, 2019, 000(012): 234-235.

[2] Deng Shuiqing. A brief analysis of the application of regional culture in urban brand image $[\mathrm{J}]$. Beauty and Times: City, 2019, 783(01): 119-120

[3] Zhang Chenyang. "Looking for" roots and "creating" personality-Talking about urban brand image from regional culture Design [J]. Hunan Packaging, 2019, 34(01): 117-120.

[4] Zhang Aipeng. Tianjin city brand image building from the perspective of regional culture [J]. Packaging Engineering, 2020, 41(10): 307-312.

[5] Ruan Xunmiao. Analysis on the application of Dongguan regional cultural symbols in urban brand image design [J]. China National Expo, 2019 (16).

[6] Yang Yiweng, sun Guohui, Tao Xiaobo. Cognition, emotion and intention of Beijing's brand image Measurement [J]. Urban Problems, 2019 (5): 34-45.

[7] Zhan Zihua. The construction and management of Guangzhou's urban image from the perspective of visual rhetoric-a comment on "number" Positioning and communication of urban brand image in the era of Chinese characters [J]. Research on Science and Technology Management, 2020, 40(18): 279-279.

\section{Author Profile}

Jia You, female, from Yancheng, Jiangsu Province, born in November 1991, a teaching assistant in the School of Fine Arts and Design, Yancheng Normal University, with a master's degree. Main research directions: visual communication design, art design, etc). Tel: 15051885025. Address: Jia You 15051885025, Yuelongwan garden 6, Kaifang Avenue, Yancheng City, Jiangsu Province. 